Хренов Н.А.

\title{
От перформанса в его актуальных формах к культурному прецеденту. Статья вторая
}

Аннотация: Обсуждаемым в данной статье предметом является творческая личность как публичная личность. Она может выражать себя в разных формах. В данном случае из всех возможных форм выделяется и рассматривается та, в которой на первый план выходит протестное начало. Конкретным выражением такой формы предстают такие виды современного искусства, как перформанс и хэппенинг, особенно те их образцы, в которых подчеркнуто протестное начало. Ощущаемый в них радикализм облегчает выявление аспектов деятельности художника, способствующих трансформации творческой личности в личность публичную. Перформианс и хэппенинг - такие формы, принадлежность которых к искусству не столь очевидна. Они воспринимаются маргинальными и не включаются в традиционную систему искусств. Их радикальные протестные проявления часто оказываются юридически наказуемыми. Однако юридические оценки не облегчают, а усложняют вынесение эстетических оценок. Чтобы преодолеть неопределенность статуса таких форм, необходимо их рассмотреть как феномены культуры, имеющие прецеденты в прошлом. Непосредственным их предшественником является то, что в Древней Руси называли юродством. Подобный культурологический ракурс исследования творческой личности предпринимается впервые. Опираясь на исследования А. ван Геннепа и В. Тэрнера, автор выявляет латентный признак деятельности творческой личности, называемый лиминальностью, т.е. необходимостью и способностью выражать чувство протеста, понимаемого как протест не только против власти, но и общества, закосневшего в конформизме. В доиндустриальных обществах носитель лиминальности, т.е. юродивый представал сакральной фигурой, не подлежащей преследованию со стороны власти. В секуляризированных обществах ее носителем выступает художник, как и создаваемые им образы героев. Современной формой выражения духа лиминальности оказываются хэппенинги и перформансы.

Ключевъе слова: Творческая личность, перформанс, хэппенинг, публичная личность, юродство, авангард, лиминальность, анти-поведение, сакральность, секулярность.

Review: A creative personality as a public figure is the topic of this article. The said personality can express itself in different forms. In this particular case among all possible forms the author is emphasizing and considering the one where the protest is coming to the fore. Such forms of the contemporary art as performance and happening, and most of all those pieces of art which are laying a special emphasize on the protest, are appearing as a concrete expression of this form. Radicalism appearing in these art forms aids detecting aspects of artist's creativeness which are promoting transformation of any creative person to a public figure. Pertain of performance and happening to art it is not obvious. These art forms are perceived as marginal one and are exclusive of the conventional art system. More often than not their radical protest is liable to prosecution. However legal evaluation does not facilitate but complicate esthetic evaluating. In order to overcome the doubtful status of these forms, it is necessary to consider them as cultural phenomenon with past precedents. "Yurodstvo" (idiotic action) of the times of Ancient Rus is their immediate predecessor. This is the first attempt to analyze the creative personality at such culturological angel. Based on researches of $A$. van Gennep and W. Turner, the author is revealing a latent character in creative person's activity, which is known as liminality, in other words, a necessity and ability to express protest which is not only a protest against the power, but as protest against the society stagnating in conformism. In pre-industrial societies any bearer of liminality, i.e. a wacky, was a sacred person, who should not suffer persecution of authorities. In secularized societies the artist and images of his/her heroes are bearers of liminality. And happenings and performances are the contemporary forms for expressing the spirit of liminality.

Keywords: Liminality, avan-garde, yurodstvo (idiotic action), rublic figure, happening, performance, creative personality, anti - behavior, sacral, secularity. 
B первой части статьи мы поставили вопрос о творческой личности как публичной личности, способной себя выражать в разных формах. Из всех возможных форм мы выбрали и начали рассматривать те, в которых на первый план выходит подчеркнутое протестное начало. Конкретным выражением такой формы предстают такие виды современного искусства, как перформанс и хэппенинг и особенно те их проявления, в которых на первый план выходит протестное начало. Ощущаемый в них радикализм облегчает выявление тех сторон деятельности художника, которые способствуют превращению творческой личности в личность публичную. Однако как перформанс, так и хэппенинг - такие формы, принадлежность которых к современному искусству, как и вообще к искусству, не столь очевидна. Во всяком случае, они кажутся маргинальными и не включаются в традиционную систему видов искусства, которая является одной из значимых проблем эстетики.

Утверждению их столь неопределенного статуса способствует и то, что радикальные протестные их проявления часто оказываются юридически наказуемыми. Однако юридические оценки не облегчают, а усложняют вынесение эстетических оценок. Чтобы преодолеть неопределенность статуса таких форм, попробуем подразумевать под ними не столько художественный, сколько культурный факт. Иначе говоря, посмотрим на эти факты с точки зрения культурологического подхода. Это предполагает их рассмотрение в больших длительностях истории, поскольку время культуры отличается от времени социального.

Как мы уже успели показать, непосредственным предшественником хэппенингов и перформансов является то, что в Древней Руси называли юродством, которое тоже характеризуется ярко выраженным протестом. Исторический прецедент, т.е. юродство позволяет выявить особый, можно сказать, латентный признак творческой личности как публичной личности. Опираясь на исследования А. ван Геннепа и В. Тэрнера, мы обозначим этот признак как лиминальность, т.е. необходимость и способность выражать чувство протеста, понимаемого не только как протест против власти, но и как протест против общества, против конформистского образа жизни.

В доиндустриальных обществах носитель лиминальности представал сакральной фигурой, не подлежащей преследованию со сто- роны власти. В секуляризированных обществах ее носителем выступает художник, как и создаваемые им образы героев. Современной формой выражения духа лиминальности оказываются хэппенинги и перформансы. Культурологическое рассмотрение этих форм позволит понять, что за представляющими ту или иную эпоху в разных обликах конкретными носителями лиминальности оказывается одна из основополагающих функций культуры, которая всегда была, есть и будет. Она предохраняет общество от ложных путей развития, способствуя утверждению той социальной нормы, в соответствии с которой, как выразился А. Солженицын, необходимо «жить не по лжи».

Нас в первую очередь интересует смысл образа художника не только как профессионала, творческой личности, деятельность которой целиком и полностью объясняется целями искусства, но еще и как публичной личности. Если в деятельности художника как профессионала, творца мы прекрасно ориентируемся, то вот что касается художника как символа публичности, то в этом еще следует разбираться. Какие смыслы следует вкладывать в словосочетание «публичная личность», когда мы имеем в виду художника? В каком случае можно говорить о художнике как публичной личности? Что вообще подразумевается под этим, вторым ликом художника? Ведь очевидно, что называть публичной личностью можно далеко не каждого художника. Что делает художника публичной личностью?

Чтобы ответить на все эти вопросы, необходимо совершить первый шаг - отделить факт искусства от факта культуры. Как мы уже договорились, факт культуры не обязательно имеет художественный смысл. Но если эти два уровня в образе художника объединяются, то мы, видимо, как раз и будем иметь возможность называть художника публичной личностью. Такой синтез искусства и публичности может иметь значительный эффект не только для искусства, но и для общества. Лишь в этом случае и происходит контакт между художником и публикой. Судя по всему, стихия публичности вообще не возникает или не становится реальной, если она не получает выражения в соответствующих символах. Но этим символом и будет публичная личность.

Когда М. Бахтин говорит о плутах, шутах и дураках, он подчеркивает их основную функцию, - восстановление публичности как значимого признака человека. Не существует 
полноценной личности без приобщенности к публичности. «Им присуща - пишет он - своеобразная особенность и право - быть чужими в этом мире, ни с одним из существующих жизненных положений этого мира они не солидаризируются, ни одно их не устраивает, они видят изнанку и ложь каждого положения. Поэтому они могут пользоваться любым жизненным положением лишь как маской. У плута еще есть нити, связывающие его с действительностью; шут и дурак - «не от мира сего» и потому имеют особые права и привилегии. Фигуры эти и сами смеются, и над ними смеются. Смех их носит публичный народно - площадной характер. Они восстанавливают публичность человеческого образа: ведь все бытие этих фигур, как таковых, сплошь и до конца вовне, они, так сказать, все выносят на площадь, вся их функция к тому и сводится, чтобы овнешнить (правда, не свое, а отраженное чужое бытие, - но другого у них и нет)» [1,c. 309].

В этой бахтинской идее площади, а, еще точнее, карнавальности уже ощущается смысл публичности как значимого выражения духа культуры как коллективного, а не индивидуального начала. В том, что такой тип личности возникает, видимо, проявляется психология публичности как безличного, но в то же время и весьма необходимого образования. Публичность организуется и принимает какие-то определенные формы по мере того, как возникает публичная личность, обладающая харизматическими признаками, способностью гипнотически действовать на публику, ее увлекать и вести за собой. Можно утверждать, что выявление сути публичности невозможно без публичных фигур. Видимо, только публичным фигурам удается выявить ее смысл, ее природу, как, собственно, и ощутить ее. Акт, совершаемый публичной личностью, есть акт трансформации. Но эта трансформация касается не только художника. Это трансформация массы как аморфного, неструктурного образования в нечто единое. Именно публичной личности дано спровоцировать в массе не связанных между собой индивидов некое единство, которое, может быть, более точно можно назвать родовым.

Но, как ни парадоксально, такое единение на основе приобщенности каждого индивида к роду возможно ценой выхода из «структуры», а под ней следует понимать не только социум, но и культуру. Вот почему публичная личность в форме юродивого - это всегда вы- ход из культуры, всегда трансформация, чреватая отрицательной реакцией со стороны как власти, так и массы.

Прибегая к М. Бахтину как авторитету при выявлении природы и функций шута и плута, мы все же должны отдавать отчет в том, что в древнейшей архетипической формуле публичности философ усматривает лишь то, что способно подчеркнуть смысл смеха, т.е. того, что и является предметом его исследования. На самом же деле, как деятельность шута, как, впрочем, и деятельность юродивого приоткрывает реальность целого института, возникновение которого связано с ранними эпохами в истории человечества, с эпохами культурогенеза. Целого института, как, впрочем, и осуществляемых им функций. Пожалуй, лишь в свете выявления природы и функций этого института приоткрывается и еще один и отнюдь не второстепенный смысл искусства.

Не случайно, когда А. Панченко дает характеристику древнерусского юродивого, он не может не упомянуть и о более древних традициях, характерных и для других древних культур. Речь не идет лишь об эпохе раннего христианства. Так, он вспоминает о кинизме как неприятии общепринятых норм поведения [2, с. 8o]. Однако юродство сближается также и с мусульманскими дервишами. Как и юродивые, они тоже преследовали умерщвление плоти. Их представления, связанные с глотанием пылающих углей, змей, скорпионов, осколков стекла, тоже предполагали толпу и были зрелищем [2, с. 80].

Конечно, М. Эпштейну удалось обнаружить в авангарде не только его художественные, но и культурные аспекты. Но сближая юродство и авангард, он приводит примеры исключительно из футуризма. Но даже и в великолепном очерке А. Панченко о древнерусском юродстве есть ограничения. Как уже отмечалось, он полагает, что юродство - национальное явление, характерное лишь для России, что, конечно, неверно. Нам же нужно понять перформансы и хэппенинги как универсальное явление, характерное для самых разных культур. Ведь сегодня они в еще большей степени активны в западной, а не только в русской культуре [3., с. 11].

Что касается Р. Сеннета, который, собственно, предметом своего исследования сделал публичную личность [4, ], рассматривая характерный для Нового и Новейшего времени ее вариант, то и ему не удалось выявить смысл и функции публичной личности. Р. Сеннет 
предстает социологом, и его вовсе не интересует функционирование в социуме архетипических образов.

Пожалуй, смысл таких фигур, как шут и юродивый точнее и глубже удалось выявить английскому этнологу В. Тэрнеру. Его концепция позволит отыскать точное обозначение для самых разных феноменов, связанных с осуществлением столь необходимых функций, причем необходимых особенно в тех культурах, в которых улавливается пафос мессианства. Как известно, смысл мессианства связан с провозглашением некоего (обычно религиозного) идеала, который должен быть воплощен в жизни.

Концепция В. Тэрнера позволит также приблизиться к пониманию творческой личности как публичной личности. Расширяя круг фигур, к которому принадлежат юродивые (русская традиция) и шуты (западная традиция) за счет некоторых литературных и кинематографических персонажей, и включая в него, в том числе, религиозных пророков и художников, В. Тэрнер пишет: «Пророки и художники имеют склонность к лиминальности и маргинальности, это «пограничные люди», которые со страстной искренностью стремятся избавиться от клише, связанных со статусом и исполнением соответствующей роли, и войти в жизненные отношения с другими людьми - на деле или в воображении. В их произведениях можно увидеть проблески этого неиспользованного эволюционного потенциала человечества, который еще не воплотился в конкретную форму и не зафиксирован структурой» [5, с. 198).

Суждение В. Тэрнера нуждается в толковании. Во всяком случае, необходимо расшифровать смысл используемых им в этом проницательном суждении, которое, как нам представляется, позволяет дать определение художника как порогового типа личности и того типа художника, который сегодня пытается утвердить себя в арт - практиках, понятий. Нужно расшифровать такие понятия, как «лиминальность», «маргинальность», «структура».

Что касается маргинальности таких фигур, то это вещь достаточно привычная и знакомая по эстетике постмодернизма. Как известно, для постмодернистов это предпочитаемый тип художника - нонконформиста, способного совершать деконструкцию эпистемы. А вот что касается понятия «лиминальность», то применительно к художнику как публичной личности оно нуждается в более детальной расшифровке. Это понятие позволяет более точно представлять те художественные и культурные процессы, что в переходных для разных обществ состояниях постоянно возрождаются. Но именно такое состояние в XX веке человечество и переживает. Это обстоятельство явилось предметом нашего внимания в специальных публикациях [6].

Кстати, мысль об активизации юродства в переходные эпохи высказывается и А. Панченко. Так, им констатируется расцвет юродства, характерный для ХУ - первой половины ХУІІ веков [2, с. 72]. Стоит ли доказывать, что для русской истории XУІІ век оказался одним из самых переходных. Может быть, и в самом деле правы те, кто XX век сближает с XУІІ веком. Такая параллель проводилась, например, В. Топоровым [7].

Как мы уже успели отметить, такая переходность, касающаяся не только социума, но и культуры (а в XУІІ веке происходила переориентация с византийской традиции на западную), характерна для XX века. Именно она провоцирует нарушение преемственности в эволюции художественных процессов и реабилитацию, казалось бы, забытых и ушедших в прошлое психологических комплексов. Они сегодня возрождаются в тех хэппенингах и перформансах, которые выше были названы и которые, несомненно, несут на себе печать протеста.

Используя понятие «лиминальность», В. Тэрнер прибегает к теории этнолога Арнольда ван Геннепа [8]. Предметом исследования А. ван Геннеп сделал обряды, вызванные к жизни во всех культурах, чтобы облегчить людям переживание переходных эпох. Переходы, связанные с разрушением сложившихся форм и укладов жизни, бывают весьма болезненными, а иногда просто ставят людей на грань жизни и смерти. Полагаю, не следует объяснять, что это такое. Мы это сегодня особенно ощущаем. Такие ситуации хотелось бы преодолевать с минимальными издержками и незначительными последствиями. Для осуществления этих функций и были вызваны к жизни переходные обряды.

В переходе как переходе из одного состояния в другое А. ван Геннеп выделяет две проблемные точки: во - первых, разделение, разрыв, грань, порог (с лат. limen ) и, во - вторых, соединение. Собственно, термин «порог» мы делаем ключевым, используя его для характеристики типа личности, избегающего растворения в структуре и при- 
нятия какой-то определенной социальной роли. Иногда принятие на себя такой роли является временным, что соответствует лишь какому-то периоду, в особенности, кризисному [9, с. 142]. Так, известно, что носитель исихастского мироощущения Савва Новый перестал быть юродивым и вернулся к иноческой жизни [2, с. 75]. Однако некоторые эту роль закрепляют за собой навсегда.

Собственно, как свидетельствует история, потребность в таком типе публичной личности в русской истории существует, как уже отмечалось, всегда. Она продолжает существовать и после реформ Петра I в секуляризированном варианте. Это обстоятельство может иметь далеко идущие последствия. Если принять во внимание гипотезу В. Шубарта [10] о том, что каждый тип культуры вызывает к жизни и особый тип личности, который может быть обозначен как базовый, то можно поставить вопрос и о присутствии в русской культуре специфического типа личности. Возможно, что в данном случае тип личности, получающий выражение в юродстве как весьма заметном феномене (а А. Панченко утверждает, что и исключительном феномене), может оказаться для русской культуры базовым типом личности.

Это позволяет более точно представлять, что такое ментальность, да, собственно, и идентичность русских. Иначе говоря, лиминальность оказывается признаком ментальности русских вообще. Юродство как в его средневековых, так и в его секулярных формax сопровождает и не может не сопровождать функционирование русской культуры на всем ее протяжении. Следовательно, ее можно фиксировать не только в юродстве, а в самых разных формах и жанрах. Печать того, что характерно для юродивых, обнаруживается в образе царя (мы уже приводили пример с Иваном Грозным), сказочных персонажей, богатырей и таких фольклорных персонажах, как «разбойник».

Лиминальных типов ни в коем случае нельзя считать индивидуалистами и анархистами. Так, лиминальное поведение богатыря Б. Успенский приводит, чтобы обозначить характерный признак русской средневековой культуры, который он называет анти - поведением [11, с. 460]. Обратимся, например, к былине под названием «Илья Муромец в ссоpe c князем Владимиром». Обида богатыря возникла потому, что князь Владимир не позвал его на пир. И вот следствие: «И он берет- то как свой тугой лук разрывчатой, / А он стрелочки берет каленые, / Выходил Илья он да на Киев -град, / И по граду Киеву стал он похаживать / И на матушки божьи церкви погуливать, / На церквах-то он кресты вси да повыломал, / Маковски он золочены все повыстрелял...» [12, с. 103]. Ну, просто большевик этот Илья Муромец, раз он кресты на церкви «выламывает».

Однако речь в данном случае идет о распространенном для средневековой культуры феномене анти - поведения. Под ним Б. Успенский понимает «обратное, перевернутое, опрокинутое поведение - иными словами, поведение наоборот» [11, с. 460]. По мнению исследователя, оно исключительно характерно для культуры Древней Руси, как и вообще для всякой архаической и средневековой культуры. Проявлением этого комплекса как раз и предстает то, что Б. Успенский называет святотатством, примером которого служит перформанс О. Кулика «Миссионер», когда он обращает рыб в христианство. Применительно к юродству иногда используется слово «кощунство». Так, это слово А. Панченко употребляет применительно к поведению Ивана Грозного, его перевоплощению в юродивого [2, с. 77] В наше время такими кощунницами совершенно серьезно называли в одной из телепередач арт - группу «Пусси Райт», имея в виду «Панк-молебен» в храме Христа Спасителя. Собственно, юродивые как раз и предстают выразителями духа анти - поведения.

Носителями анти - поведения, т.е. кощунственного поведения в русской истории предстают, как показывает Б. Успенский, так называемые «разбойники». Так, Б. Успенский приводит примеры с поведением Степана Разина и Емельяна Пугачева. Например, Степан Разин демонстративно отказывался при венчании от церковной обрядности, предлагая брачующимся в пляске кружиться вокруг дерева. Пренебрежение по отношению к церковной обрядности выказывал и Емельян Пугачев. Он мог входить в церковь, не сняв шапку и садиться на престол в алтаре. В данном случае можно говорить об имитации поведения юродивого.

А. ван Геннеп выделяет три стадии переходной ситуации: прелиминальную (отделение индивида или группы от сообщества, в которое он до перехода был включен), собственно лиминальную (промежуточная стадия, когда индивид отделяется от одного сообщества, но еще не становится членом другого сообщества) 
и, наконец, постлиминальную, когда происходит включение индивида в новое сообщество [8, с. 15]. Согласно А. ван Геннепу, получается, что прелиминальная и постлиминальная фазы связаны с определенной иерархической структурой социума, частью которой является каждый индивид. Он неизбежно, в силу принципа иерархии обязан играть в социуме определенную роль. Но раз это является жестким условием социализации и нормального функционирования социума, т. е., если выражаться языком В. Тэрнера, «структуры», то избежать этого врастания в социум невозможно. В конечном счете, этим путем все и проходят.

Что касается лиминальной стадии, то в ней есть свои преимущества. Длительность этой стадии можно продлить, как это, например, делают молодые бунтари во второй половине XX века, в жизни которых можно констатировать много карнавального [13]. Более того, эту стадию можно превратить в отдельную сферу социума, и таким образом лиминальную ситуацию институционализировать. В этом случае должны появиться носители и выразители соответствующей лиминальной сфере ментальности. Это и есть пороговые индивиды. В эпоху Средневековья они проявляли себя в юродстве как религиозном явлении, а позднее в сфере искусства.

Это, конечно, не означает, что функция, выражением которой в Древней Руси явилось юродство, с некоторых пор закрепляется только за искусством. Это также не означает и того, что это единственная и основополагающая функция искусства. Но она для искусства также существенна. Возможно, только она и позволяет глубже осознать его предназначение.

Вот как представляет В. Тэрнер лиминальные фигуры, которые он находит в самых разных сферах. «Свойства лиминальности или лиминальных personal («пороговых людей») - пишет он - непременно двойственны, поскольку и сама лиминальность и ее носители увертываются или выскальзывают из сети классификаций, которые обычно размещают «состояния» и положения в культурном пространстве. Лиминальные существа ни здесь, ни там, ни то, ни се; они - в промежутке между положениями, предписанными и распределенными законом, обычаем, условностями и церемониалом. Поэтому их двусмысленные свойства выражаются большим разнообразием символов в многочисленных обществах, ритуализирующих специальные и культурные переходы. Так, лиминальность часто упо- добляется смерти, утробному существованию, невидимости, темноте, двуполости, пустыне, затмению солнца или луны» [5, с. 169].

Так, М. Форман, например, обнаружил носителя лиминальности в клинике для душевнобольных (фильм «Пролетая над гнездом кукушки»), а М. Антониони - в студенческой среде, в субкультуре «новых левых». У него лиминальность и в самом деле ассоциируется, как у В. Тэрнера, с пустыней. Действие в его фильме «Забриски Пойнт» развертывается на фоне пустыни. Другой свой фильм он вообще назвал «Затмение». Так, В. Розанов посвятил этой фигуре целое исследование [14].

Спрашивается, какой же смысл в институционализации и такой сферы, и таких носителей лиминальной ментальности? Смысл состоит в том, что ни один известный в истории тип социума, который В. Тэрнер называет «структурой», не способен предоставить возможность для выражения каких-то таких особенностей человеческого потенциала, без которых не могут существовать ни индивиды, ни все человечество.

В связи с этой невозможностью реализации человеческого потенциала хочется вспомнить изложенную В. Райхом структуру личности, состоящую из трех уровней. То, о чем мы говорим, у него представлено третьим уровнем личности, т.е. тем потенциалом личности, который связан со склонностью к сотрудничеству и любви. Этот потенциал соотносим с космосом, и он реализуется лишь в искусстве [15]. Что касается первых двух уровней, то один из них связан с социализацией и воспитанием, а второй - подсознательный. Он образован импульсами жестокости, садизма, сладострастия и жадности. Он возникает как следствие подавления первичных биологических влечений. Возможность реализации потенциала, соответствующего третьему уровню, приоткрывается лишь в лиминальной ситуации, когда отдельные фигуры, а ими могут быть или художники, мыслители или религиозные реформаторы, вспоминают об идеальных отношениях между людьми, которые в «структуре», т.е. в социуме недостижимы. Здесь уместна мысль Платона о мире идей и о способности к воспоминанию об этом мире избранных индивидов, которые и есть художники и мыслители.

Носителей лиминальных ценностей, активизирующихся на второй, лиминальной фазе, но угасающих при переходе на третью - постлиминальную фазу, можно обозначить 
лиминальными или пороговыми типами или фигурами, находящимися по отношению к любому проявлению «структуры» на дистанции. Мы этот тип обозначаем как пороговый тип. Несомненно, неспособность включиться в новую иерархию и новую «структуру» способствует формированию особой психологии таких лиминальных типов, их крайней неспособности к практической жизни, к адаптации. Но проигрывая в практических сферах, они демонстрируют исключительные способности в других сферах, в частности, в искусстве. Собственно, это обстоятельство характеризует и творческую личность. Ведь, как пишет последователь К. Юнга Э. Нойманн, такой тип личности противостоит культурному канону, ибо не способен жертвовать тем, что цивилизация стремится вытеснить в бессознательное, сделать несуществующим. В противоположность требованиям культурного канона творческий человек ценит архетипическую реальность [16][

Отдельного и особого разговора заслуживает лиминальность не только применительно к отдельным, т.е. лиминальным индивидам. Потребность в них может быть потребностью самого социума, предрасположенного в своей истории постоянно возобновлять лиминальные ситуации, т.е. ситуации выхода из структуры. Ведь активность юродивых как носителей лиминальности характерна, как уже отмечалось, для переходных ситуаций. Эпохи массовых движений и революций свидетельствуют о массовых проявлениях лиминальности. В какой-то степени русские предрасположены к утверждению лиминальности. Этот комплекс у русских улавливает Г. Флоровский. Он пишет, что в незакрепленности в «структуре», в способности к перевоплощениям есть «опасность не найти самого себя» («Душа теряется, сама себя теряет, в этих переливах исторических впечатлений и переживаний. Точно не поспевает сама к себе возвращаться, слишком многое привлекает ее и развлекает, удерживает в инобытии. И создаются в душе какие - то кочевые привычки, - привычка жить на развалинах или в походных шатрах. Русская душа плохо помнит родство. И всего настойчивее в отрицаниях и отречениях») [17, с. 501].

Разумеется, активность лиминальных типов связана не только с карнавалом и юродством. Такие типы можно отыскать в фольклоре, в частности, в сказке. А. Панченко обращает внимание на созвучность поведения юродивых со сказками о дураках. Как он убежден, сказка - значимый источник для понимания феномена юродства. «Иван - дурак, - пишет А. Панченко - похож на юродивого тем, что он - самый умный из сказочных героев, а также тем, что мудрость его прикровенна. Если в экспозиции и в начальных эпизодах сказки его противостояние миру выглядит как конфликт глупости и здравого смысла, то с течением сюжета выясняется, что глупость эта притворная или мнимая, а здравый смысл сродни плоскости и подлости» [2, с. 100].Вот среди этого рода лиминальных персонажей М. Бахтин и нашел фигуру трикстера как обобщающего для обозначения более конкретных носителей лиминальности вроде шута, дурака, плута и т.д. имени. Лиминальность как мировосприятие у него обозначена знаменитым термином «карнавализация».

Критическое отношение творцов некоторых образцов арт - практики к реальности, их негативизм, порождающий скандалы и головную боль представителей силовых структур, как это, например, происходило в случае с перформансом арт - группы «Война», объясняется вовсе не их дерзостью, неуправляемостью и стремлением к хулиганству. Во - первых, как правило, они представляют некое сообщество, пусть и маргинального типа, в чем мы убеждаемся, пытаясь понять смысл образования таких сообществ, как битники, хиппи или панки. Они выражают мировосприятие такого сообщества. Во - вторых, смысл лиминальных фигур, в том числе, художников и мыслителей не ограничивается ментальностью маргинальных групп. Сами эти маргинальные группы, как и конкретные носители и выразители их ментальности, оказываются медиаторами тех невоплощенных пока еще в реальности и в истории, но весьма необходимых ценностей. Без них ни индивиды, ни человечество существовать не могут. Значит, мировосприятие какой - то общности способно со временем стать универсальным мировосприятием. Многое свидетельствует о том, что, например, утопии, для которых также характерна лиминальность, оказываются актуальными на протяжении всей истории. В человеке и человечестве есть некие ценности, которые, несмотря на совершенствование общества, так и не удается реализовать.

Вслед за В. Тэрнером следует подчеркнуть, что существование нереализованных в структуре и приоткрываемых в лиминальных состояниях ценностей является условием рождения мифов, символов, ритуалов, фило- 
софских систем и произведений искусства. Сообщество, ускользающее от «структуры», В. Тэрнер называет «коммунитас» [5, с. 199]. Ее представляют маргиналы, чужаки, любые «приниженные» типы. Так, он демонстрирует полный набор таких типов, находимых им в мифах, литературе, наконец, в самой жизни. «Народная литература, - пишет он - кишит такими символическими героями, как «святые нищие», «третьи сыновья», «портняжки», «простаки», которые сбивают спесь с высокопоставленных персонажей, низводя их до общечеловеческого уровня простых смертных. И опять - таки, в классическом «вестерне» мы все читали о таинственном «незнакомце» без имущества и без имени, который восстанавливает этическое и правовое равновесие в среде местной политической власти, устраняя неправедных секулярных «боссов», угнетавших малых мира сего. Члены презираемых или бесправных этнических либо культурных групп играют главные роли в мифах и сказках как представители или выразители общечеловеческих ценностей. Среди них знамениты: милосердный самарянин, еврей - скрипач Ротшильд в чеховской новелле «Скрипка Ротшильда», марктвеновский беглый раб - негр Джим в «Гекльберри Финне» и Соня у Достоевского - проститутка, которая спасает Раскольникова, как бы ницшеанского «сверхчеловека», в «Преступлении и наказании» [5, с. 183].

Как мы убеждаемся, лиминальное мировосприятие вторгается в литературу - и не только в авантюрную (вестерн), но и в классическую (Л. Толстой, Достоевский, Чехов). Остается назвать лишь какие-то произведения кино. Под этим лиминальным углом зрения Л. Трауберг, например, осмыслил великих американских комиков, в том числе, Чарли Чаплина, представив их выразителями «жизни наизнанку» [18].

Можно также называть и более близкие нам, современные фильмы. Например, отечественные фильмы, поставленные в эпоху брежневского застоя по сценариям Г. Горина. Это, прежде всего, касается его героя - барона Мюнхгаузена (фильм «Тот самый Мюнхгаузен»), полюбившегося по понятным и выше изложенным причинам массовой публике. Представляя кинодраматургию Г. Горина, М. Захаров, преуспевший в создании спектаклей и фильмов по сценариям Г. Горина, героев этого драматурга соотнес с постоянно воспроизводимым архетипом.
Но дело не только в этом. М. Захаров и в самом авторе, драматурге увидел то, что в свое время в авторе романов обнаружил М. Бахтин, а именно, шута, трикстера. «Прежде всего, они (шуты, дураки, трикстеры - Н. Х.) - пишет М. Бахтин - оказали влияние на постановку самого автора в романе (и его образ, если он как-то раскрывается в романе), на его точку зрения» [1, с. 310]. Именно эти фигуры помогли найти и утвердить автору романа позицию «безучастного участника жизни», «вечного соглядатая и отражателя ее» [1, с. 310].

Касаясь Г. Горина как автора, М. Захаров словно иллюстрирует это положение М. Бахтина. «Главная тема, - пишет он - которая до некоторой степени объединяла им (Гориным - Н. Х.) сочиненное: Шут! Острослов, борец, романтик, любимец своего народа. Таким был Тиль Уленшпигель, совершенно иным был шут Мюнхгаузен, изощренным шутом глубинного интеллекта был Джонатан Свифт, каждый год устраивавший собственные похороны. И конечно, Менахем Мендел из «Поминальной молитвы»... В последние годы жизни Гриша сделал ряд блистательных и гомерически смешных монологов. Они читались им, как бы, между прочим, на некоторых театральных праздниках и юбилеях. Ничего умнее и остроумнее я не слышал в своей жизни. И только теперь, в последнее время, я стал догадываться, что это был не просто мудрый и веселый комедиограф. Может быть, Горин тоже был Шутом. Шутом новой формации, который ненадолго посетил наше многострадальное отечество, чтобы занять законное место рядом с Уленшпигелем, Мюнхгаузеном, поющими слугами Калиостро, Теркиным, Бумбарашем, Юрием Никулиным» [19]. Как из этого суждения следует, М. Захаров ощутил лиминальный нерв русского, но, в том числе, и советского искусства. Точнее было бы сказать, искусства советского периода.

Исходя из всего сказанного, можно сделать окончательный вывод, который может показаться странным, парадоксальным. Такой вывод покажется странным потому, что проблема остается неразрешимой. Обнаруженный нами пороговый тип личности имеет разные формы выражения. Мы коснулись лишь той разновидности этого типа, что связана с арт практиками, в которых протест оказывается, в том числе, и протестом против привычных эстетических норм, против искусства вообще. Это выход не только из эстетики, но и из культуры. Именно такую ситуацию сегодня пере- 
живаем мы, чем можно объяснить расцвет арт - практик различного рода.

В заключение повторим еще раз: одна из линий современного искусства, а именно, так называемые арт - практики, проявлением которых является и перформансы О. Кулика, и «Панк-молитва» арт - группы «Пусси райт», продолжают древнюю традицию, которая ярко проявилась в средневековой культуре в образе юродивого. Что же касается преследования творцов со стороны власти, то, как говорится, каждый институт, а юродство и его поздние варианты, несо- мненно, является древнейшим институтом культуры, занимается своим делом. Новые юродивые делают свое дело, и здесь, конечно, требуется смелость и способность совершать такие акции. Иметь смелость и способность совершать поступок. Что же касается силовых структур, то они понимают порядок по-своему. Соответственно, принимаются все возможные меры. Хотелось бы, чтобы в их действиях было больше понимания и мудрости. Так повелось издавна. Наверное, наше время не является исключением. Судя по всему, так будет и в будущем.

\section{Библиография:}

1. Бахтин М. Вопросы литературы и эстетики. М., 1975;

2. Лихачев Д., Панченко А., Понырко Н. Смех в Древней Руси.Л., 1984;

3. Голдберг Р. Искусство перформанса. От футуризма до наших дней. М., 2014;

4. Сеннет Р. Падение публичного человека. М., 2009;

5. Тэрнер В. Символ и ритуал. М., 1983;

6. Хренов Н. Переходность как следствие колебательных процессов между культурой чувственного и культурой идеационального типа // Переходные процессы в русской художественной культуре. Новое и Новейшее время (Ответственный редактор Н. А. Хренов). М., 2003;

7. Топоров В. Московские люди ХУІІ века (К злобе дня) // Philologia slavica. К 70-летию академика Н. И. Толстого. М., 1993;

8. Геннеп ван А. Обряды перехода. М., 1999;

9. Щепанская Т. Кризисная сеть (Традиции духовного освоения пространства) // Русский Север. К проблеме локальных групп. СПб., 1995;

10. Шубарт В. Европа и душа Востока. М., 1997;

11. Успенский Б. Анти-поведение в культуре Древней Руси // Успенский Б. Избранные труды., т. 1. Семиотика истории. Семиотика культуры. М., 1996;

12. Былины. Л., 1986;

13. Давыдов Ю., Роднянская И. Социология контркультуры (Инфантилизм как тип мировосприятия и социальная болезнь)., М., 1980;

14. Розанов В. Люди лунного света. М., 1990;

15. Райх В. Психология масс и фашизм. СПб, 1997;

16. Нойманн Э. Творческий человек и трансформация // Нойманн Э. Психоанализ и искусство. М., 1996;

17. Флоровский Г. Пути русского богословия. Киев., 1991;

18. Трауберг Л. Избранные произведения в 2-х т., т. 2. Мир наизнанку. М., 1984;

19. Горин Г. Тот самый Мюнхгаузен. СПб., 200

20. Петров В.О. Акционизм Джона Кейджа: основные формы и специфика их воплощения // Культура и искусство. - 2014. - 4. - С. 444 - 456. DOI: 10.7256/2222-1956.2014.4.12721.

21. Петров В.О. Новаторские образы искусства XX века: в ракурсе эпатажа // Культура и искусство. - 2013. 5. - C. 562 - 569. DOI: 10.7256/2222-1956.2013.5.9151.

\section{References (transliterated):}

1. Bakhtin M. Voprosy literatury i estetiki. M., 1975;

2. Likhachev D., Panchenko A., Ponyrko N. Smekh v Drevnei Rusi.L., 1984;

3. Goldberg R. Iskusstvo performansa. Ot futurizma do nashikh dnei. M., 2014;

4. Sennet R. Padenie publichnogo cheloveka. M., 2009;

5. Terner V. Simvol i ritual. M., 1983; 
6. Khrenov N. Perekhodnost' kak sledstvie kolebatel'nykh protsessov mezhdu kul'turoi chuvstvennogo i kul'turoi ideatsional'nogo tipa // Perekhodnye protsessy v russkoi khudozhestvennoi kul'ture. Novoe i Noveishee vremya (Otvetstvennyi redaktor N. A. Khrenov). M., 2003;

7. Toporov V. Moskovskie lyudi KhUII veka (K zlobe dnya)// Philologia slavica. K 70-letiyu akademika N. I. Tolstogo. M., 1993;

8. Gennep van A. Obryady perekhoda. M., 1999;

9. Shchepanskaya T. Krizisnaya set' (Traditsii dukhovnogo osvoeniya prostranstva) // Russkii Sever. K probleme lokal'nykh grupp. SPb., 1995;

10. Shubart V. Evropa i dusha Vostoka. M., 1997;

11. Uspenskii B. Anti-povedenie v kul'ture Drevnei Rusi // Uspenskii B. Izbrannye trudy., t. 1. Semiotika istorii. Semiotika kul'tury. M., 1996;

12. Byliny. L., 1986;

13. Davydov Yu., Rodnyanskaya I. Sotsiologiya kontrkul'tury (Infantilizm kak tip mirovospriyatiya i sotsial'naya bolezn')., M., 1980;

14. Rozanov V. Lyudi lunnogo sveta. M., 1990;

15. Raikh V. Psikhologiya mass i fashizm. SPb, 1997;

16. Noimann E. Tvorcheskii chelovek i transformatsiya // Noimann E. Psikhoanaliz i iskusstvo. M., 1996;

17. Florovskii G. Puti russkogo bogosloviya. Kiev., 1991;

18. Trauberg L. Izbrannye proizvedeniya v 2-kh t., t. 2. Mir naiznanku. M., 1984;

19. Gorin G. Tot samyi Myunkhgauzen. SPb., 200

20. Petrov V.O. Aktsionizm Dzhona Keidzha: osnovnye formy i spetsifika ikh voploshcheniya // Kul'tura i iskusstvo. - 2014. - 4. - C. 444 - 456. DOI: 10.7256/2222-1956.2014.4.12721.

21. Petrov V.O. Novatorskie obrazy iskusstva KhKh veka: v rakurse epatazha // Kul'tura i iskusstvo. - 2013. - 5. - C. 562 - 569. DOI: 10.7256/2222-1956.2013.5.9151. 